\title{
ARTICLE
}

\section{Real-time observation of cation exchange kinetics and dynamics at the muscovite-water interface}

\author{
Sang Soo Lee ${ }^{1}$, Paul Fenter ${ }^{1}$, Kathryn L. Nagy ${ }^{2} \&$ Neil C. Sturchio ${ }^{3}$
}

Ion exchange at charged solid-liquid interfaces is central to a broad range of chemical and transport phenomena. Real-time observations of adsorption/desorption at the molecularscale elucidate exchange reaction pathways. Here we report temporal variation in the distribution of $\mathrm{Rb}^{+}$species at the muscovite (001)-water interface during exchange with $\mathrm{Na}^{+}$. Time-resolved resonant anomalous $\mathrm{X}$-ray reflectivity measurements at $25^{\circ} \mathrm{C}$ reveal that $\mathrm{Rb}^{+}$desorption occurs over several tens of seconds during which thermodynamically stable inner-sphere $\mathrm{Rb}^{+}$slowly transforms to a less stable outer-sphere $\mathrm{Rb}^{+}$. In contrast, $\mathrm{Rb}^{+}$adsorption is about twice as fast, proceeding from $\mathrm{Rb}^{+}$in the bulk solution to the stable inner-sphere species. The Arrhenius plot of the adsorption/desorption rate constants measured from 9 to $55^{\circ} \mathrm{C}$ shows that the pre-exponential factor for desorption is significantly smaller than that for adsorption, indicating that this reduced attempt frequency of cation detachment largely explains the slow cation exchange processes at the interface.

\footnotetext{
${ }^{1}$ Chemical Sciences and Engineering Division, Argonne National Laboratory, 9700 South Cass Avenue, Argonne, Illinois 60439, USA. ${ }^{2}$ Department of Earth and Environmental Sciences, University of Illinois at Chicago, 845 West Taylor Street, MC-186, Chicago, Illinois 60607, USA. ${ }^{3}$ Department of Geological Sciences, University of Delaware, 255 Academy Street, Newark, Delaware 19716, USA. Correspondence and requests for materials should be addressed to S.S.L. (email: sslee@anl.gov) or to P.F. (email: fenter@anl.gov).
} 
C harged solid-liquid interfaces are primary sites for a wide array of chemical reactions including ion adsorption and molecular uptake ${ }^{1-5}$, atalysis ${ }^{6-10}$ and energy storage ${ }^{11-14}$. Fundamental understanding of these processes depends on the ability to see changes in interfacial structure during reactions within the electrical double layer (EDL) ${ }^{15-19}$. Recent work ${ }^{20-22}$ demonstrated that the EDL structure at solid-water interfaces can be complex, having coexisting ions in different hydration states including inner-sphere (IS) complexes that adsorb at the surface in a partially solvated state and outer-sphere (OS) complexes that adsorb in a fully solvated state (Fig. 1a). Distinguishing these adsorbed species requires determination of the interfacial structure at the molecular scale. To date, knowledge of the dynamic variations in these adsorbed counterions largely relies on computational studies ${ }^{4,23-25}$. In contrast, experimental validations of ion dynamics at interfaces are scarce primarily because of difficulties in monitoring molecular-scale changes in the interfacial structure in situ and in real time. The reaction steps that control ion dynamics at interfaces, including reaction pathways that determine the overall reaction rates as well as energy barriers that separate distinct adsorption states within the pathways, are also not well defined.

Muscovite mica has a basal surface that is atomically flat with a known structural negative charge ( $1 \mathrm{e}^{-}$per surface area of a unit cell, $A_{\mathrm{UC}}=46.72 \AA^{2}$, corresponding to $-0.34 \mathrm{C} \mathrm{m}^{-2}$; ref. 26). Adsorption of simple alkali cations and associated changes of interfacial hydration at the muscovite (001)-water interface have been studied extensively using various approaches including surface force apparatus ${ }^{27-30}$, atomic force microscopy 31,32 , in situ X-ray surface scattering $22,33-36$ and computational simulations $34,37,38$. These studies unequivocally report that the reactivities of cations are closely related to their hydration. For example, a competitive adsorption isotherm between $\mathrm{Rb}^{+}$and $\mathrm{Na}^{+}$at the muscovite (001)-water interface revealed that the intrinsic adsorption constant $\left(\mathrm{K}_{\text {ads }}^{\circ}\right)$ for $\mathrm{Na}^{+}$on the muscovite (001) surface is substantially lower than that for $\mathrm{Rb}^{+}\left(10^{2.51 \pm 0.14}\right.$ versus $10^{4.12 \pm 0.10}$; refs 35,39$)$. The relatively weak adsorption for $\mathrm{Na}^{+}$was interpreted to result from a larger energy cost for partial dehydration of more strongly hydrated $\mathrm{Na}^{+}$compared to $\mathrm{Rb}^{+}$. The Gibbs free energy of hydration for $\mathrm{Na}^{+}$is $-365 \mathrm{~kJ} \mathrm{~mol}^{-1}$, and is significantly larger than $-275 \mathrm{~kJ} \mathrm{~mol}^{-1}$ for $\mathrm{Rb}^{+}$(ref. 40).

Differences in cation hydration can also influence adsorbed cation speciation at the interface. The distribution of $\mathrm{Rb}^{+}$ adsorbed at the muscovite (001)-water interface was determined to be a mixture of IS and OS complexes using in situ resonant anomalous X-ray reflectivity (RAXR) ${ }^{22}$ (Fig. 1). The fractional coverage of IS $\mathrm{Rb}^{+}$was $85-90 \%$, indicating that the majority of adsorbed $\mathrm{Rb}^{+}$is in a partially solvated state, in which the muscovite surface completes the solvation shell. Dominant IS adsorption of $\mathrm{Rb}^{+}$within the surface ditrigonal site of the muscovite surface also was reported from in situ atomic force microscopy ${ }^{31,32}$ and in situ crystal truncation rod (CTR) measurements ${ }^{36}$. In contrast, our understanding of the distribution of $\mathrm{Na}^{+}$adsorbed at the muscovite (001)-water interface is still elusive. Unlike $\mathrm{Rb}^{+}$, whose distribution can be determined precisely using X-ray reflectivity (XR) and RAXR techniques ${ }^{22}$, the adsorbed distribution of $\mathrm{Na}^{+}$ions is difficult to quantify by these techniques because of its small electron-density contrast with a water molecule $\mathrm{e}^{22,34,37}$ and its X-ray absorption K-edge energy $(1.071 \mathrm{keV})$ that is too low for in situ RAXR measurements. Instead, it was speculated that $\mathrm{Na}^{+}$may adsorb to the muscovite surface at a greater distance from the surface (for example, as an OS complex) on the basis of its relatively weaker adsorption strength ${ }^{35}$ and stronger hydration strength ${ }^{40}$. Computational methods have been utilized to model the adsorbed structure of $\mathrm{Na}^{+}$and the other alkali metal cations. However, the calculated structures depend strongly on the choice of force field. Molecular dynamics simulations with the Kawamura force field ${ }^{37}$ show that all alkali metal cations except $\mathrm{Li}^{+}$adsorb as an IS complex in the ditrigonal cavity of the muscovite surface ${ }^{34,37}$. This observation contrasts with results using the Skipper force field $^{41}$, which show preferential adsorption of cations on top of Al-substituted tetrahedra. The molecular dynamics simulations using the CLAYFF force field show that $\mathrm{Na}^{+}$can form two types of IS species ${ }^{38}$, instead of one dominant species as observed by the other two calculations. Overall, experimental and computational studies indicate that it is well understood that $\mathrm{Rb}^{+}$forms mostly an IS complex at the muscovite-water interface, whereas further observations are needed to understand the adsorbed structure of $\mathrm{Na}^{+}$accurately.

Here we present experimental observations of the real-time evolution of adsorbed ion coverage and speciation during exchange reactions between $\mathrm{Na}^{+}$and $\mathrm{Rb}^{+}$at the muscovite (001)-water interface. Time-resolved RAXR measurements reveal both the significant difference between cation adsorption and desorption rates and asymmetric variations in adsorbed cation speciation at $25^{\circ} \mathrm{C}$. $\mathrm{Rb}^{+}$adsorption is faster than $\mathrm{Rb}^{+}$ desorption, and appears to proceed directly to the dominant
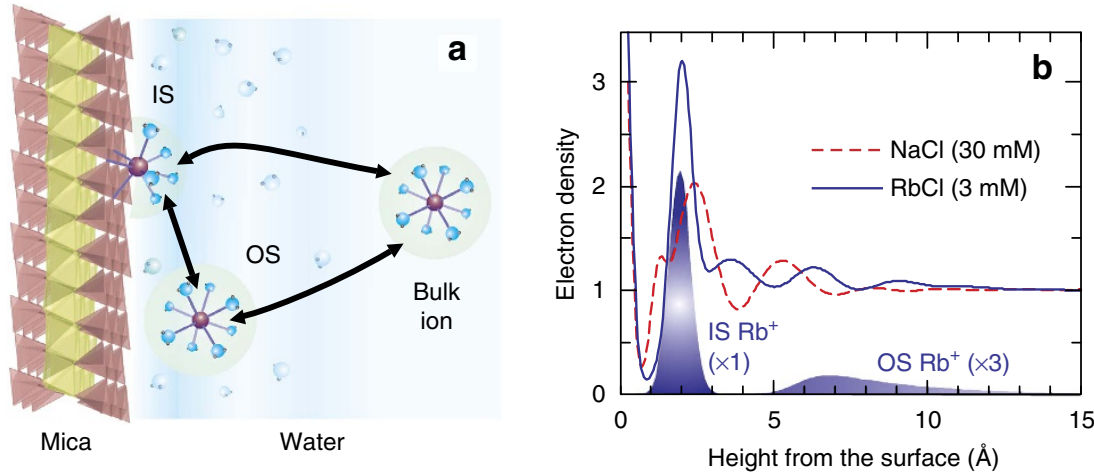

Figure 1 | Monovalent cation exchange and interfacial structure at the muscovite mica (001)-water interface. (a) Schematic of the EDL at the muscovite-water interface. Monovalent cations adsorb as a combination of partially hydrated IS and fully-hydrated OS complexes, with several potential pathways for exchange between the adsorbed and bulk solution species. (b) Interfacial structure between the mica (001) surface and $30 \mathrm{mM} \mathrm{NaCl}$ versus $3 \mathrm{mM} \mathrm{RbCl}$ solutions 22,56 . The total electron-density profiles determined by high-resolution XR are shown for the two solutions. The distribution of IS and $\mathrm{OS} \mathrm{Rb}^{+}$determined by RAXR is shown in shaded areas. The height is referenced to the average height of oxygen in the mica surface. The distribution of $\mathrm{OS} \mathrm{Rb}^{+}$is scaled vertically by a multiplicative factor of 3 for clarity. 

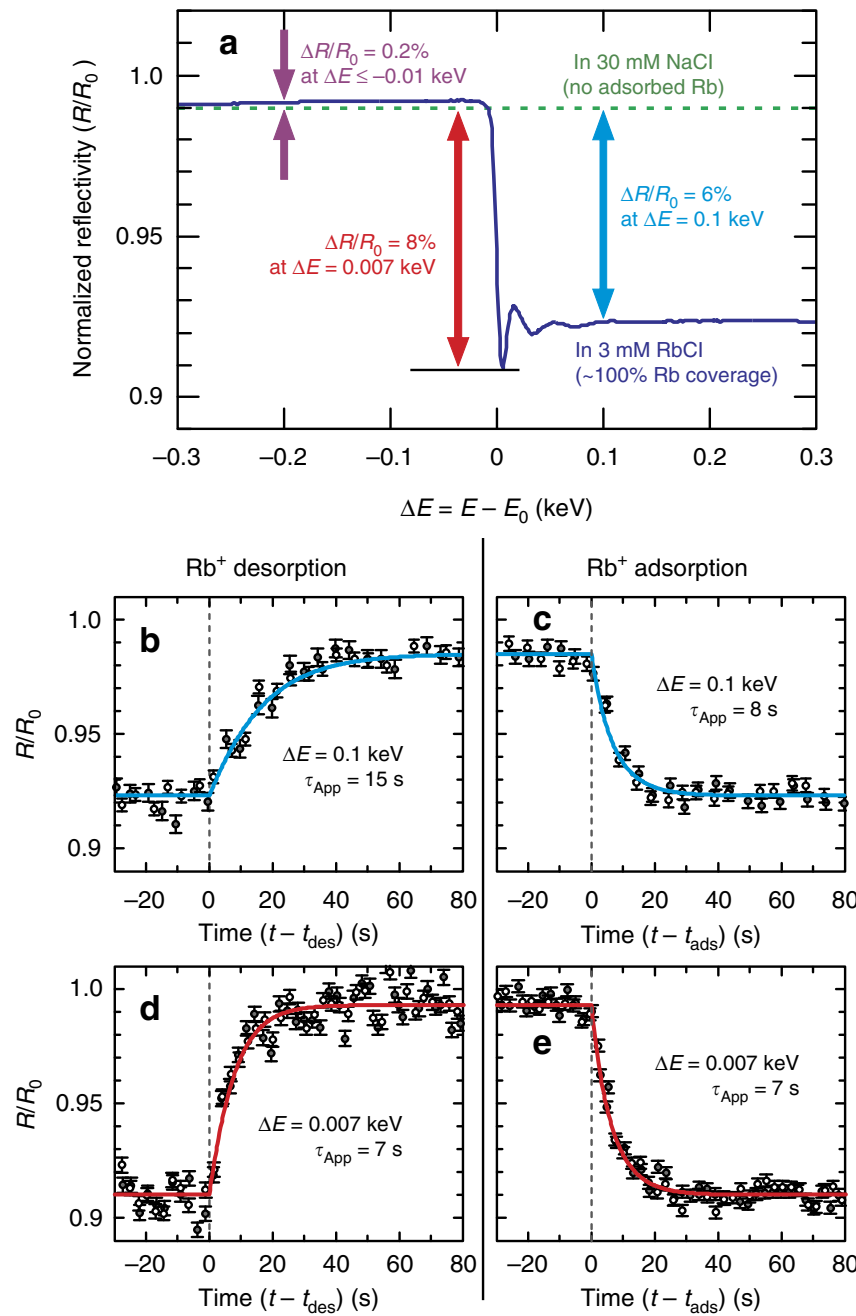

Figure 2 | Real-time X-ray reflectivity during $\mathbf{R b}^{+} / \mathrm{Na}^{+}$exchange at the muscovite mica (001)-water interface at a fixed q. (a) RAXR spectrum of muscovite (001) surface at $q=0.488 \AA^{-1}$ in $3 \mathrm{mM} \mathrm{RbCl}$ compared with that in $30 \mathrm{mM} \mathrm{NaCl}$ (ref. 22). The reflectivity $(R)$ is normalized to the non-resonant reflectivity $\left(R_{0}\right)$ calculated using the best-fit model of the non-resonant $\mathrm{XR}$ data for the mica-RbCl system ${ }^{22}$. The purple, red and blue arrows indicate the relative changes at three different photon energies $(E)$ near the $\mathrm{X}$-ray absorption K-edge energy of $\mathrm{Rb}\left(E_{0}=\sim 15.2 \mathrm{keV}\right)$. (b-e) The temporal changes in reflectivity measured at $\Delta E=0.1 \mathrm{keV}$ (and $0.007 \mathrm{keV}$ ) during $\mathrm{Rb}^{+}$desorption and adsorption, including duplicate data (open and solid circles). One s.d. error bars are calculated on the basis of the counting statistics $^{43}$. The solid curves are calculated from the best-fit first-order exchange equations where $\tau_{\text {App }}$ is the apparent time constant (Supplementary Note 3). In each plot, the time of injection of the exchanging solution (either $t_{\text {des }}$ or $t_{\mathrm{ads}}$ for $\mathrm{Rb}^{+}$desorption or adsorption, respectively) is indicated by a dashed vertical line.

IS species. In contrast, $\mathrm{Rb}^{+}$desorption is a slow stepwise process where thermodynamically stable IS $\mathrm{Rb}^{+}$transforms to $\mathrm{OS} \mathrm{Rb}^{+}$before desorption from the interface. Real-time variations in $\mathrm{Rb}^{+}$coverage at temperatures from 9 to $55^{\circ} \mathrm{C}$ indicate that slow desorption is primarily controlled by a small pre-exponential factor attributed to the multiple paths each ion can take as it desorbs. Considering that the adsorption strength (as characterized by the intrinsic adsorption constant, $K^{\circ}$ ads) is determined by the relative magnitude between adsorption $\left(k_{\mathrm{ads}}\right)$ and desorption $\left(k_{\mathrm{des}}\right)$ rate constants, we conclude that the thermodynamic stability of these cation adsorbates is effectively determined by the rate of desorption, in particular the attempt frequency of 'detachments' of ions from the muscovite-water interface.

\section{Results}

Cation exchange process and structure. Experiments were conducted using a freshly cleaved muscovite mica (001) surface in contact with two aqueous alkali metal salt solutions $(30 \mathrm{mM} \mathrm{NaCl}$ and $3 \mathrm{mM} \mathrm{RbCl}$ ). The $\mathrm{NaCl}$ concentration was chosen to be 10 times the $\mathrm{RbCl}$ concentration to mitigate the difference in adsorption constant between two cations. The intrinsic adsorption constant $K^{\circ}$ ads for $\mathrm{Rb}^{+}$on the muscovite (001) surface is about one order of magnitude higher than that for $\mathrm{Na}^{+}$ $\left(10^{4.12 \pm 0.10}\right.$ versus $10^{2.51 \pm 0.14}$; refs 35,39$)$.

Time-dependent changes in the interfacial structure during $\mathrm{Rb}^{+}$and $\mathrm{Na}^{+}$exchange were probed by using in situ timeresolved X-ray reflectivity (TXR). We utilized the resonant anomalous scattering phenomenon ${ }^{42}$ to obtain element-specific information through the variation in XR contrast as a function of photon energy. This is illustrated with a measured RAXR spectrum from the muscovite (001) surface in contact with a $3 \mathrm{mM} \mathrm{RbCl}$ solution $^{22,35}$ at momentum transfer $q=0.488 \AA^{-1}$ (refs 35,39 ) in Fig. 2a. This spectrum has a fractional modulation whose magnitude and shape are directly controlled by the coverage and average height of adsorbed $\mathrm{Rb}^{+}$, respectively ${ }^{35,42}$ Comparison of calculated RAXR spectra with and without $\mathrm{Rb}^{+}$ (that is, in $3 \mathrm{mM} \mathrm{RbCl}$ solution versus in $30 \mathrm{mM} \mathrm{NaCl}$ solution) shows strong contrast at $E>E_{\mathrm{o}}$, where $E_{\mathrm{o}}=\sim 15.2 \mathrm{keV}$ is the $\mathrm{X}$-ray absorption $\mathrm{K}$-edge energy of $\mathrm{Rb}$. The maximum contrast ( $\sim 8 \%)$ can be obtained at $\Delta E=E-E_{\mathrm{o}}=0.007 \mathrm{keV}$ where the RAXR spectrum in $3 \mathrm{mM} \mathrm{RbCl}$ has its minimum intensity.

Time-resolved XR data at $\Delta E=0.1$ and $0.007 \mathrm{keV}$ (Fig. 2b-e, respectively) were obtained while alternately flowing $\mathrm{Rb}^{+}$and $\mathrm{Na}^{+}$solutions across a muscovite (001) surface in a flow-through $\mathrm{X}$-ray transmission cell ${ }^{43}$ (Supplementary Note 1 ) at $25^{\circ} \mathrm{C}$. The reflected X-ray intensities were fully recovered after each ion exchange cycle (Fig. 2b-e), indicating that the reactions are reversible. The rates of reaction were sensitive to both the reaction direction (for example, $\mathrm{Rb}^{+}$adsorption versus desorption) and the photon energy where the XR data were measured. The apparent time constant $\left(\tau_{\mathrm{App}}\right)$ for $\mathrm{Rb}^{+}$desorption at $\Delta E=0.1 \mathrm{keV}$ was almost twice the value for $\mathrm{Rb}^{+}$adsorption (15 versus $8 \mathrm{~s}$, respectively, Supplementary Table 1 ), whereas $\tau_{\text {App }}$ values for both reaction directions are the same at a different photon energy, $\Delta E=0.007 \mathrm{keV}$. This difference in $\tau_{\mathrm{App}}$ at two photon energies indicates that the shape of RAXR spectra may change during the exchange reaction (Supplementary Note 3). In particular, the spectral shape at this specific $q$ is sensitive to the IS:OS coverage ratio $^{35,42}$, implying variations in adsorbed $\mathrm{Rb}^{+}$speciation during adsorption and desorption.

To quantify the apparent differences in response time to the choice of photon energy, a series of XR data were obtained at 34 different photon energies near $E_{\mathrm{o}}(-0.3 \leq \Delta E \leq 0.3 \mathrm{keV})$ as a function of reaction time (Fig. 3a,b). Sections parallel to the time axis are generally similar to those shown in Fig. 2, albeit with systematic energy-dependent variations in signal contrast as a function of photon energy. When the same data are viewed parallel to the energy axis, they correspond to a set of timeresolved RAXR (TRAXR) spectra, whose size and shape indicate the time-dependent variations in the $\mathrm{Rb}^{+}$distribution at the interface (Supplementary Note 3).

Selected TRAXR spectra are compared in Fig. 3c,d to visualize differences in the time-dependent changes in the RAXR spectra between $\mathrm{Rb}^{+}$desorption and adsorption. Compared with the spectrum at $t-t_{\mathrm{des}}=0 \mathrm{~s}$ (where $t_{\mathrm{des}}$ corresponds to the time 
a

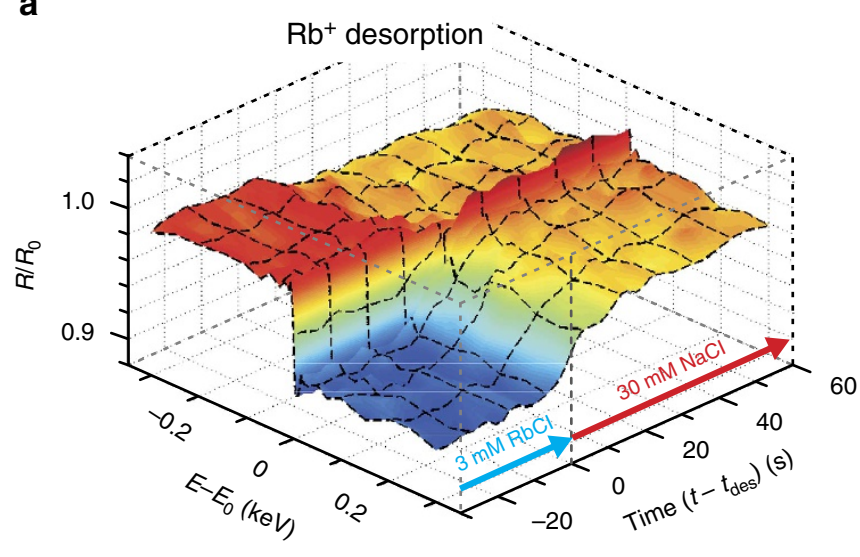

b

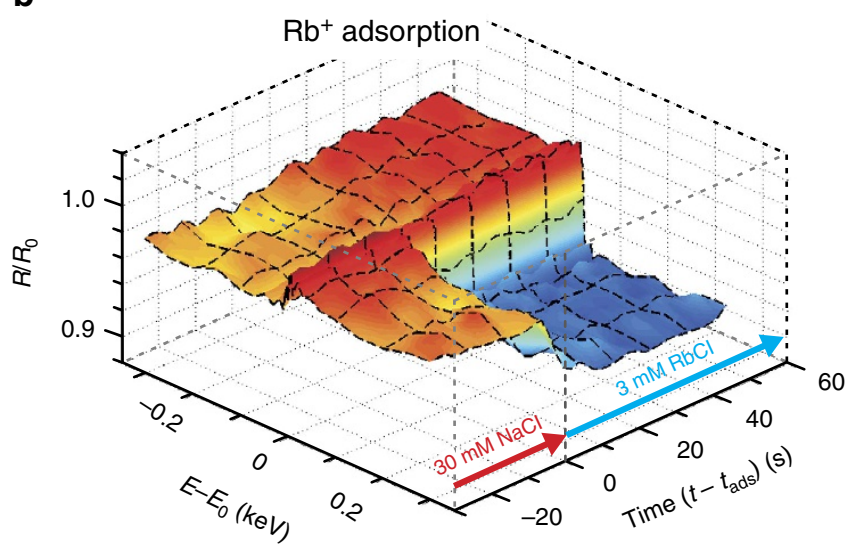

C

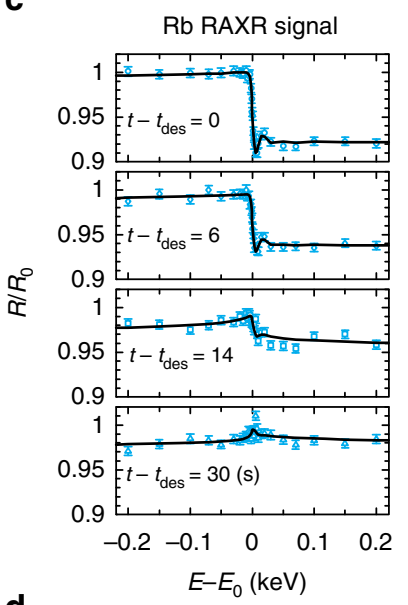

d

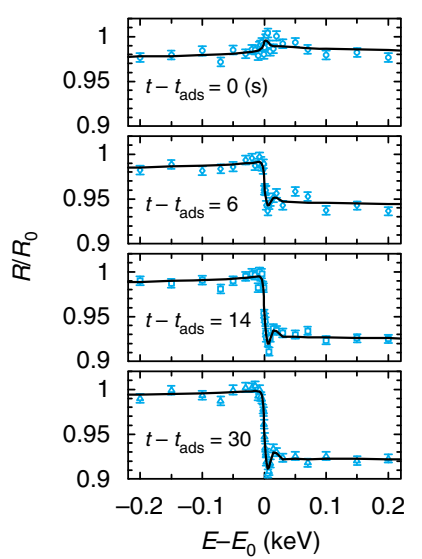

Figure 3 | TRAXR at the muscovite mica (001)-water interface. X-ray reflectivity during $\mathrm{Rb}^{+}$desorption (a) and adsorption (b) was measured as a function of photon energy $\left(\Delta E=E-E_{\mathrm{o}}\right)$ and reaction time $\left(\Delta t=t-t_{\text {des }}\right.$ or $t-t_{\mathrm{ads}}$, respectively). (c,d) TRAXR spectra sampled at four different delay times after solution exchange during $\mathrm{Rb}^{+}$desorption or adsorption. Error bars (s.d.) are derived on the basis of the counting statistics ${ }^{43}$.

when $\mathrm{Rb}^{+}$desorption started), the spectrum at $t-t_{\mathrm{des}}=14 \mathrm{~s}$ has approximately half the RAXR magnitude near $E_{\mathrm{o}}$, indicating that about half of the $\mathrm{Rb}^{+}$desorbed from the surface. In contrast, $\mathrm{Rb}^{+}$adsorption was mostly complete in the spectrum at $t-t_{\mathrm{ads}}=14 \mathrm{~s}$ (where $t_{\mathrm{ads}}$ corresponds to the time when $\mathrm{Rb}^{+}$ adsorption started), that is, the spectrum has almost the same magnitude as that at $t-t_{\mathrm{ads}}=30 \mathrm{~s}$. The spectra measured during $\mathrm{Rb}^{+}$desorption (Fig. 3c) also show a notable change in shape at $t-t_{\mathrm{des}}=14$ and $30 \mathrm{~s}$ from the spectrum at $t-t_{\mathrm{des}}=0 \mathrm{~s}$, indicating that interfacial $\mathrm{Rb}^{+}$distribution (that is, its speciation) changed during desorption ${ }^{42}$. On the other hand, the spectra (Fig. 3d) measured during $\mathrm{Rb}^{+}$adsorption show almost no shape changes.

These differences in the RAXR magnitude and shape indicate that temporal variations in the adsorbed $\mathrm{Rb}^{+}$coverage and speciation depend on the reaction direction. To quantify this relationship, the time-dependent variations in the total $\mathrm{Rb}^{+}$ coverage and IS:OS coverage ratio were derived using modelindependent RAXR analysis ${ }^{35,42}$ (Supplementary Note 4) as a function of $\mathrm{Rb}^{+}$and $\mathrm{Na}^{+}$concentrations in the cell during solution exchange (Fig. $4 \mathrm{a}, \mathrm{b}$ and see Supplementary Notes 2 and 3 for details). Temporal variations in total $\mathrm{Rb}^{+}$coverage show a significant difference in the reaction rate between desorption and adsorption (Fig. 4c,d). More than $90 \%$ of $\mathrm{Rb}^{+}$desorbed in $\sim 25 \mathrm{~s}$, whereas the same amount adsorbed within about half this time $(\sim 14 \mathrm{~s})$. This difference is correlated with the evolution of adsorbed $\mathrm{Rb}^{+}$speciation during ion exchange. The fractional coverage of $\mathrm{OS} \mathrm{Rb}^{+}\left(f_{\mathrm{OS}, \mathrm{Rb}}\right)$ increased gradually from 0.15 (the equilibrium fractional speciation) to $\sim 0.7$ during desorption. In contrast, a sudden change in $f_{\mathrm{OS}, \mathrm{Rb}}$ was observed during $\mathrm{Rb}^{+}$adsorption: $f_{\mathrm{OS}, \mathrm{Rb}}$ rapidly decreased to $\leq 0.2$ (close to the expected value of $0.1-0.15$ ) within $5 \mathrm{~s}$ after injection of the $\mathrm{RbCl}$ solution (Fig. $4 \mathrm{f}$ ), even though $\sim 20 \mathrm{~s}$ elapsed before the total $\mathrm{Rb}^{+}$coverage reached its maximum (Fig. $4 \mathrm{~d}$ ).

The time-dependent changes in the IS and OS coverages of $\mathrm{Rb}^{+}$were computed using $\theta_{\mathrm{Rb}}$ and $f_{\mathrm{OS}, \mathrm{Rb}}$. During $\mathrm{Rb}^{+}$ desorption (when the total ion coverage decreased monotonically), the coverage of OS $\mathrm{Rb}^{+}\left(\theta_{\mathrm{Rb}, \mathrm{OS}}\right)$ initially increased for $\sim 12 \mathrm{~s}$ after which it began to decrease gradually until almost all $\mathrm{Rb}^{+}$desorbed from the surface (Fig. 4g). This result indicates that the redistribution rate of $\mathrm{Rb}^{+}$between the IS and OS species is similar to the desorption rate of $\mathrm{Rb}^{+}$. This interpretation is consistent with the simulations shown in Supplementary Note 3. In contrast, the observed $\mathrm{Rb}^{+}$speciation remains nearly unchanged during adsorption, with a value consistent with the equilibrium distribution (Fig. 4h), indicating that the rate for transformation from OS to IS $\mathrm{Rb}^{+}$is significantly greater than the rate of adsorption.

Determination of cation exchange kinetics. The temporal variations in the total coverages of adsorbed $\mathrm{Rb}^{+}$and $\mathrm{Na}^{+}$were characterized by intrinsic adsorption and desorption rate constants using equations for a two-component exchange 
reaction. The derivatives of the total coverages of each ion per $A_{\mathrm{UC}}, \theta_{\mathrm{Rb}}$ and $\theta_{\mathrm{Na}}$, with respect to time, are described by

$$
\begin{aligned}
& \frac{\mathrm{d} \theta_{\mathrm{Rb}}}{\mathrm{d} t}=a_{\mathrm{Rb}}(t) k_{\mathrm{ads}, \mathrm{Rb}}\left(1-\theta_{\mathrm{Rb}}-\theta_{\mathrm{Na}}\right)-k_{\mathrm{des}, \mathrm{Rb}} \theta_{\mathrm{Rb}} \\
& \frac{\mathrm{d} \theta_{\mathrm{Na}}}{\mathrm{d} t}=a_{\mathrm{Na}}(t) k_{\mathrm{ads}, \mathrm{Na}}\left(1-\theta_{\mathrm{Rb}}-\theta_{\mathrm{Na}}\right)-k_{\mathrm{des}, \mathrm{Na}} \theta_{\mathrm{Na}}
\end{aligned}
$$

where $a_{\mathrm{Rb}}(t)$ and $a_{\mathrm{Na}}(t)$ are time-dependent ion activities calculated using the extended Debye-Hückel equation ${ }^{44}$ and cation concentrations in bulk solution (Fig. 4a,b and Supplementary Note 2$)$, and $k_{\mathrm{ads}, \mathrm{Rb}}, k_{\mathrm{des}, \mathrm{Rb}}, k_{\mathrm{ads}, \mathrm{Na}}$ and $k_{\mathrm{des}, \mathrm{Na}}$ are the adsorption and desorption rate constants for $\mathrm{Rb}^{+}$and $\mathrm{Na}^{+}$. These equations were solved numerically to determine the rate constants that best describe the real-time changes in $\mathrm{Rb}^{+}$ coverage. Although the $\mathrm{Na}^{+}$coverages were not measured, their kinetic constants could be estimated indirectly on the basis of the effect on $\theta_{\mathrm{Rb}}$ as described in equations (1 and 2).

There are similarities as well as differences in interfacial kinetics between the two cations. For both, the intrinsic rate constants for adsorption $\left(k_{\mathrm{ads}}\right)$ are higher by several orders of magnitude than the intrinsic rate constants for desorption $\left(k_{\text {des }} ;\right.$ Table 1$)$. Between these two cations, the intrinsic adsorption rate constant for $\mathrm{Rb}^{+}$is more than 10 times higher than that for $\mathrm{Na}^{+}$, whereas the desorption rate constants for both cations are similar to each other. For both cations, the ratios $k_{\text {ads }} / k_{\text {des }}$ are similar to the intrinsic adsorption constants determined previously from the adsorption isotherm measurements at $25^{\circ} \mathrm{C}$ (refs 35,39), confirming the consistency between static and dynamic measurements ${ }^{45}$.

Temperature-dependent cation exchange kinetics. Both the XR signals (at $q=0.488 \AA^{-1}$ and $\Delta E=0.007$ or $0.1 \mathrm{keV}$; Fig. $2 \mathrm{~b}-\mathrm{e}$ ) and the adsorbed $\mathrm{Rb}^{+}$coverage values derived from TRAXR analyses (Fig. $4 \mathrm{c}, \mathrm{d}$ ) at $25^{\circ} \mathrm{C}$ show monotonic variations as a function of reaction time (Supplementary Note 6). Using this relationship, the time-dependent variations in $\mathrm{Rb}^{+}$coverage, referred to as 'apparent $\mathrm{Rb}^{+}$coverage' hereafter, can be estimated from the TXR data measured at these specific momentum transfer and photon energy. This method effectively bypasses the need for the full set of TRAXR data, and therefore allows us to measure the adsorption and desorption kinetics using the TXR data at selected photon energies $(\Delta E=0.007$ or $0.1 \mathrm{keV})$ at four additional temperatures $\left(9,16,40\right.$ and $\left.55^{\circ} \mathrm{C}\right)$.

The time-dependent variation in apparent $\mathrm{Rb}^{+}$coverage (Fig. 5a) shows a strong dependence on temperature. As predicted from classical kinetic theories ${ }^{45}$, the reaction rates were slowest at the lowest temperature $\left(9^{\circ} \mathrm{C}\right)$, and increased with temperature. At $55^{\circ} \mathrm{C}$, the measured coverage variations almost overlap those calculated by assuming equilibration with the instantaneous solution composition (determined by the rate of solution exchange within the sample cell $)^{43}$, indicating that the intrinsic reaction rates are difficult to determine precisely at this temperature.

The reaction rate constants at each temperature (Fig. 5b) were derived from the data using equations ( 1 and 2). Adsorption rate constants were about 4 orders of magnitude higher than desorption rate constants for $\mathrm{Rb}^{+}$at all studied temperatures. The rate constants differed by 2 orders of magnitude for $\mathrm{Na}^{+}$. The rate constants for both $\mathrm{Rb}^{+}$and $\mathrm{Na}^{+}$generally show trends following a classical Arrhenius law ${ }^{45}$, although deviations from this linearity were observed for the rate constants of $\mathrm{Na}^{+}$at higher temperatures where the measurements are less precise.

The derived rate constants were fit to the Arrhenius equation

$$
k_{\mathrm{i}}=A_{\mathrm{i}} \exp \left(-E_{\mathrm{a}, \mathrm{i}} / R \mathrm{~T}\right)
$$

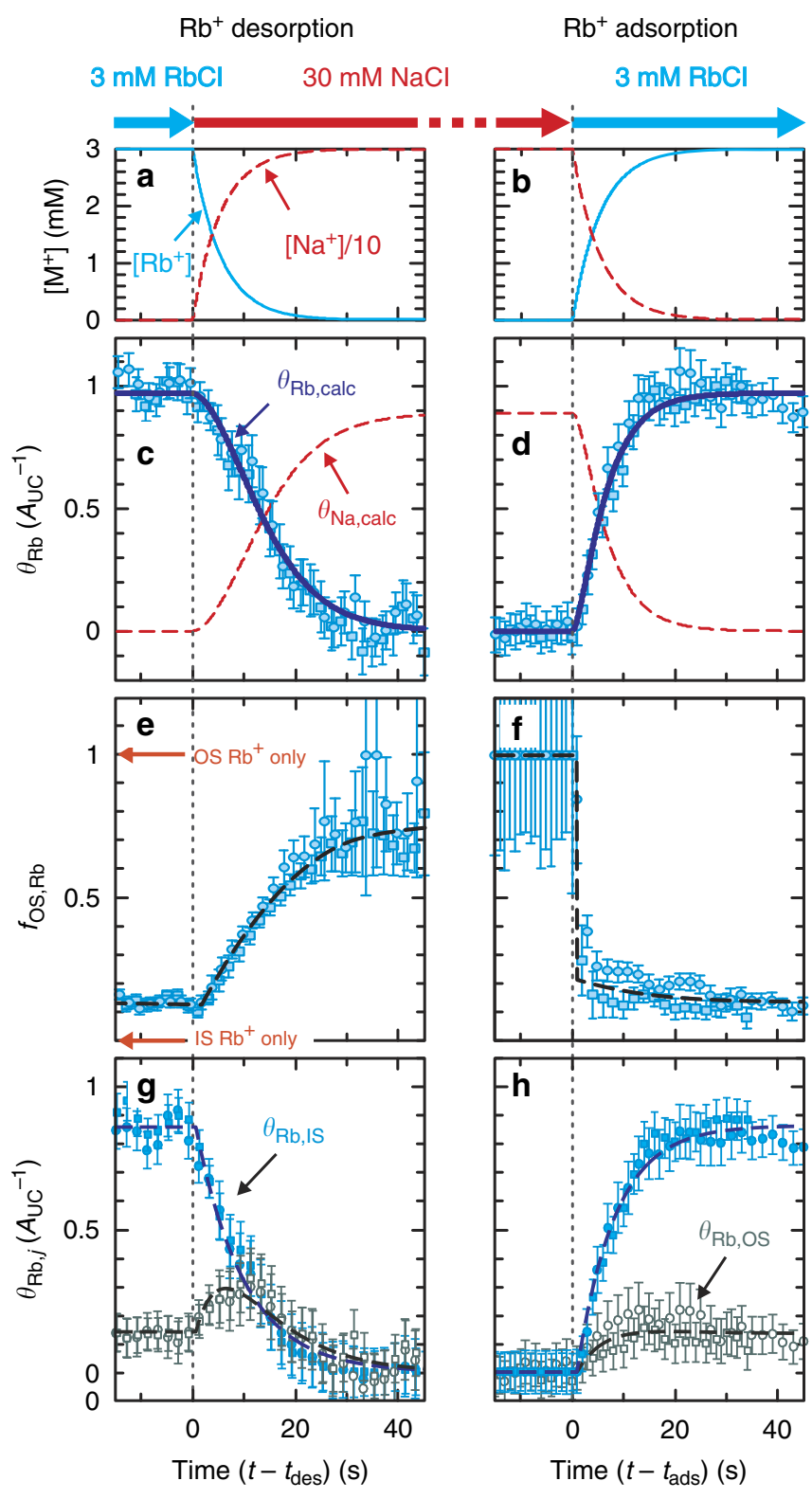

Figure 4 | Temporal changes in the coverage and speciation of $\mathbf{R b}^{+}$ adsorbed at the muscovite mica (001)-water interface during desorption and adsorption. (a,b) The calculated concentrations of $\mathrm{Rb}^{+}$and $\mathrm{Na}^{+}$in the experiment cell (see Supplementary Notes 1 and 2 for details). (c,d) Temporal variations in the total $\mathrm{Rb}^{+}$coverage $\left(\theta_{\mathrm{Rb}}\right)$ during $\mathrm{Rb}^{+}$desorption and adsorption. Each data set was duplicated (circle and square symbols). The thick solid blue lines represent the total $\mathrm{Rb}^{+}$coverage $\left(\theta_{\mathrm{Rb}, \text { calc }}\right)$ calculated from the best-fit model (Table 1$)$. The variations of $\mathrm{Na}^{+}$coverage $\left(\theta_{\mathrm{Na} \text {,calc }}\right)$ calculated from the same model are also plotted in red dashed lines for comparison. $(\mathbf{e}, \mathbf{f})$ Temporal variations in the fractional coverage of OS $\mathrm{Rb}^{+}$ ( $\left.f_{\mathrm{OS}, \mathrm{Rb}}=\theta_{\mathrm{Rb}, \mathrm{OS}} / \theta_{\mathrm{Rb}}\right)$ during desorption and adsorption. (g,h) Variations in the coverages of individual $\mathrm{Rb}^{+}$species $\left(\theta_{\mathrm{Rb}, j}\right.$ where $j=\mathrm{IS}$ or OS) were calculated as $\theta_{\mathrm{Rb}, \mathrm{IS}}=\theta_{\mathrm{Rb}}\left(1-f_{\mathrm{OS}, \mathrm{Rb}}\right)$ and $\theta_{\mathrm{Rb}, \mathrm{OS}}=\theta_{\mathrm{Rb}} f_{\mathrm{OS}, \mathrm{Rb}}$. The error bars represent s.d. uncertainties of the parameters derived from the least-squares analysis.

The dashed lines are included to guide the eye.

where $k_{\mathrm{i}}, A_{\mathrm{i}}$ and $E_{\mathrm{a}, \mathrm{i}}$ are the intrinsic rate constant, Arrhenius pre-exponential factor (an attempt frequency for a reaction) and activation energy for reaction $\mathrm{i}$; $R$ is the gas constant; and $\mathrm{T}$ is the temperature. The activation energies for $\mathrm{Rb}^{+}$adsorption and desorption are similar (26 and $31 \mathrm{~kJ} \mathrm{~mol}^{-1}$, respectively, Table 2). 
Table 1 | Kinetic and thermodynamic properties of adsorption and desorption of $\mathbf{R b}^{+}$and $\mathrm{Na}^{+}$at the muscovite mica (001)water interface at $25^{\circ} \mathrm{C}$.

\begin{tabular}{|c|c|c|c|c|c|}
\hline Cations & Reaction & $k\left(s^{-1}\right)$ & $\boldsymbol{k}_{\text {ads }} / \boldsymbol{k}_{\mathrm{des}}$ & $\boldsymbol{K}_{\text {ads }}^{\circ}$ & $\Delta G^{\circ}{ }_{\text {hyd }}\left(\mathrm{kJ} \mathrm{mol}^{-1}\right)$ \\
\hline$\overline{\mathrm{Rb}^{+}}$ & Ads & $2.1( \pm 0.6) \times 10^{3}$ & $10^{4.2( \pm 0.2)}$ & $10^{4.12( \pm 0.10)}$ & -275 \\
\hline $\mathrm{Na}^{+}$ & $\begin{array}{l}\text { Ads } \\
\text { Des }\end{array}$ & $\begin{array}{c}1.3( \pm 0.5) \times 10^{2} \\
0.25( \pm 0.03)\end{array}$ & $10^{2.7( \pm 0.3)}$ & $10^{2.51( \pm 0.14)}$ & -365 \\
\hline
\end{tabular}

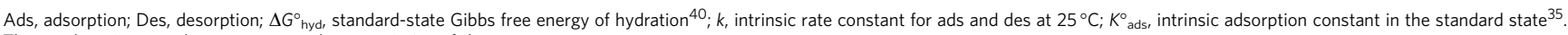
The numbers in parentheses are one s.d. uncertainties of the parameters.
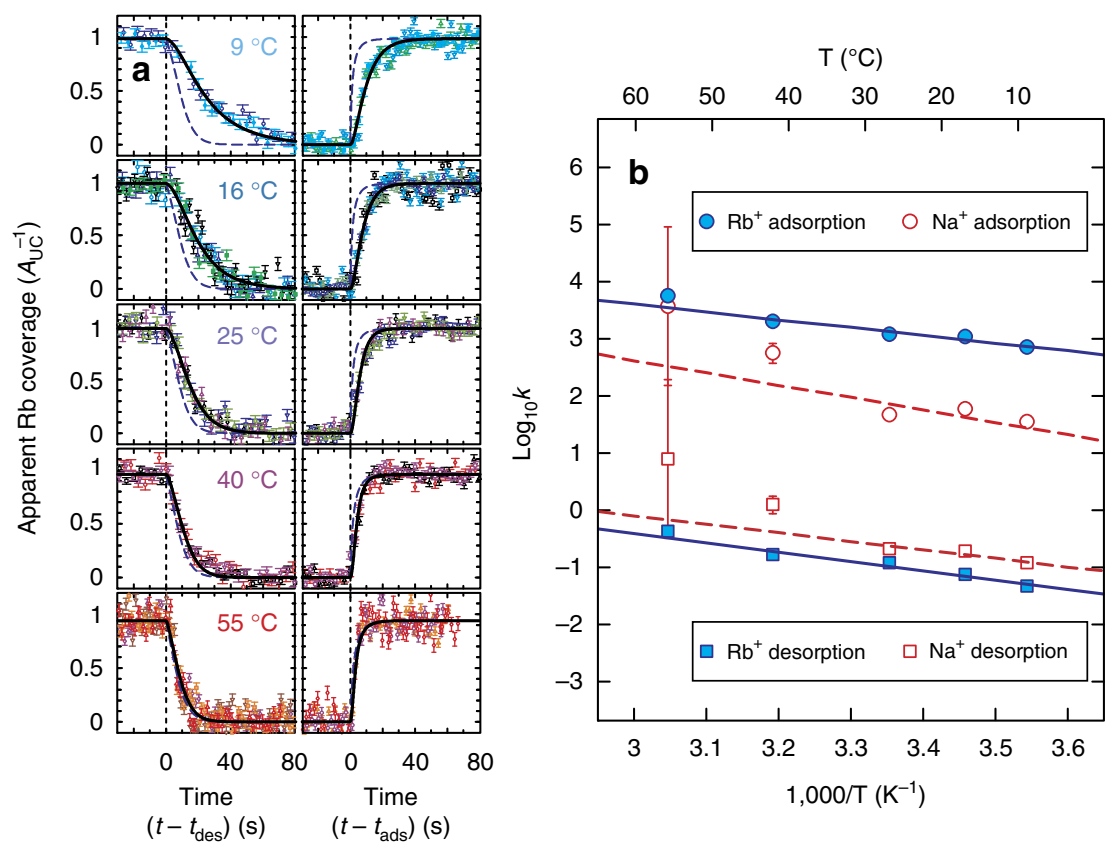

Figure 5 | Exchange kinetics between $\mathbf{R b}^{+}$and $\mathbf{N a}{ }^{+}$adsorbed at the muscovite-water interface as a function of temperature. (a) Time-dependent change in apparent $\mathrm{Rb}^{+}$coverage measured during $\mathrm{Rb}^{+}$desorption (left) and adsorption (right) at 9, 16, 25, 40 and $55^{\circ} \mathrm{C}$. Each symbol with a different colour represents one independent data set. The s.d. error bars were calculated from the counting statistics ${ }^{43}$. Dotted vertical lines show the time when the solution exchange started (either $t_{\text {des }}$ or $t_{\mathrm{ads}}=0$ for $\mathrm{Rb}^{+}$desorption and adsorption, respectively). The solid lines show the $\mathrm{Rb}^{+}$coverages calculated from the best-fit models using equations ( 1 and 2 ). The long-dashed lines are the equilibrium coverages calculated using the intrinsic adsorption constants ${ }^{35}$ and ion activities ${ }^{44}$, and the known solution exchange rates (Supplementary Note 2), and show the limit of the measurements for the fast reaction kinetics at $55^{\circ} \mathrm{C}$. (b) Arrhenius plot of the measured kinetic rate constants as a function of inverse temperature. The derived constants for Rb ${ }^{+}$adsorption (solid circles) and desorption (solid squares) are shown with the best-fit lines (solid lines). The rate constants for $\mathrm{Na}^{+}$adsorption (open circles) and desorption (open squares) obtained from this model, along with the best-fit trend lines (dashed lines), are shown for comparison.

\begin{tabular}{|c|c|c|c|}
\hline Cations & Reaction & $E_{\mathrm{a}}\left(\mathrm{kJ} \mathrm{mol}^{-1}\right)$ & $A\left(s^{-1}\right)$ \\
\hline \multirow[t]{2}{*}{$\overline{\mathrm{Rb}^{+}}$} & Ads & $26.1( \pm 0.3)$ & $8.5( \pm 1.1) \times 10^{7}$ \\
\hline & Des & $30.9( \pm 0.3)$ & $3.0( \pm 0.4) \times 10^{4}$ \\
\hline \multirow[t]{2}{*}{$\mathrm{Na}^{+}$} & Ads & $40.2( \pm 1.2)$ & $2( \pm 1) \times 10^{9}$ \\
\hline & Des & $29.7( \pm 0.5)$ & $5( \pm 1) \times 10^{4}$ \\
\hline
\end{tabular}

However, the pre-exponential factor for adsorption is over three orders of magnitude greater than for desorption. For $\mathrm{Na}^{+}$, the Arrhenius fit showed good agreement with the low-temperature data, but not the higher temperature rate constants determined with larger uncertainties. The $E_{\text {a,ads }}$ value for $\mathrm{Na}^{+}$was $\sim 14 \mathrm{~kJ} \mathrm{~mol}^{-1}$ higher than for $\mathrm{Rb}^{+}$, and the $A_{\mathrm{ads}}$ value was $\sim 20$ times higher than that for $\mathrm{Rb}^{+}$. Both $E_{\mathrm{a} \text {,des }}$ and $A_{\mathrm{des}}$ values for $\mathrm{Na}^{+}$were similar to those for $\mathrm{Rb}^{+}$, consistent with the similar $k_{\text {des }}$ values observed for these two cations at $25^{\circ} \mathrm{C}$ (Table 1).

\section{Discussion}

Time-resolved RAXR reveals that $\mathrm{Rb}^{+}$desorption is a slow stepwise reaction in which the thermodynamically stable IS $\mathrm{Rb}^{+}$ transforms to the less stable OS $\mathrm{Rb}^{+}$before it desorbs from the interface. In contrast, the adsorption of $\mathrm{Rb}^{+}$proceeds rapidly to the stable adsorption mode in which $\mathrm{Rb}^{+}$adsorbs dominantly as an IS species. These asymmetric variations on $\mathrm{Rb}^{+}$speciation with reaction direction can be understood in the context of the free energy profile of interfacial $\mathrm{Rb}^{+}$(Fig. 6). The relative free energies of adsorption for the IS and OS species, the widths of the free energy minima and a lower limit for the energy barrier 


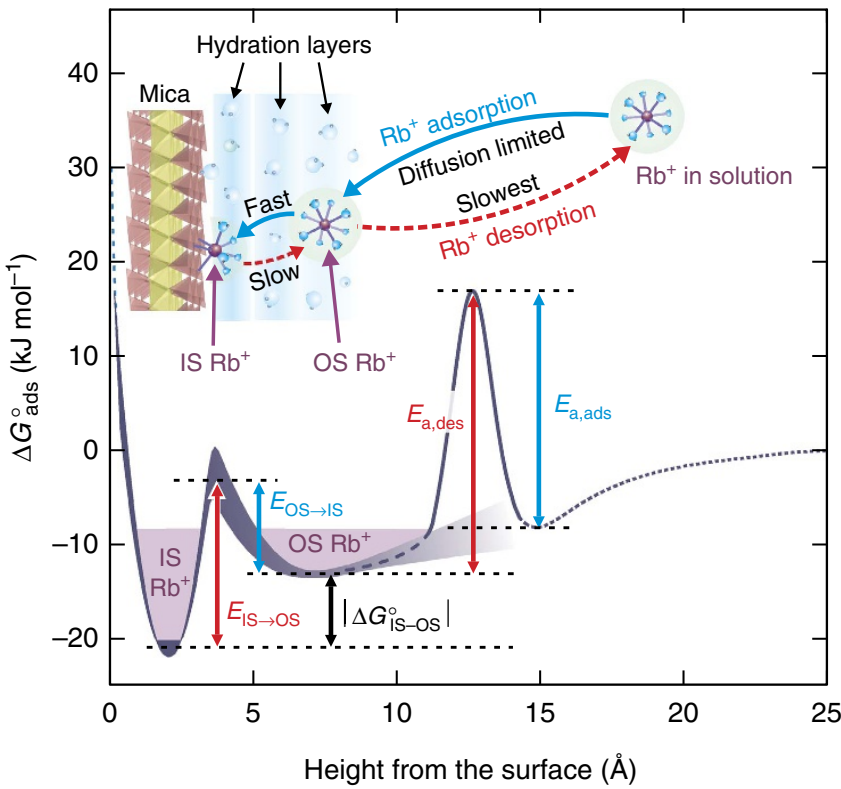

Figure 6 | Free energy profile for $\mathbf{R b}{ }^{+}$adsorbed at the muscovite mica (001)-water interface. The free energy profile $\left(\Delta G^{\circ}{ }_{\text {ads }}\right)$ is computed as a function of height ( $z$ ) up to $\sim 10 \AA$ using the electron-density profile of adsorbed $\mathrm{Rb}^{+}$reported previously ${ }^{22}$ (Supplementary Note 5 ). The thickness of the line corresponds to one s.d. of uncertainty ${ }^{65}$ of the free energy in units of $\mathrm{kJ} \mathrm{mol}^{-1}$. The $\Delta G^{\circ}$ ads for $z \rightarrow \infty$ was set to 0 (Supplementary Note 5). The activation energies for the transition from IS to $\mathrm{OS} \mathrm{Rb}^{+}$and from OS to IS $\mathrm{Rb}^{+}$are labelled $E_{\mathrm{IS} \rightarrow O S}$ and $E_{\mathrm{OS} \rightarrow \mathrm{IS}}$, respectively. $\Delta \mathrm{G}^{\circ}{ }_{\mathrm{IS} \text {-OS }}$ is the difference in free energy of adsorption between IS and $\mathrm{OS} \mathrm{Rb}^{+}$. The activation energies for $\mathrm{Rb}^{+}$desorption and adsorption are labelled as $E_{\mathrm{a}, \mathrm{des}}$ and $E_{\mathrm{a}, \text { ads }}$

respectively. The top schematic shows the stepwise pathways for adsorption and desorption of $\mathrm{Rb}^{+}$(indicated with blue and red arrows, respectively) at the interface.

for the transition between the IS and OS states are obtained from the electron-density profile of $\mathrm{Rb}^{+}$adsorbed on the muscovite surface derived from previous RAXR measurements ${ }^{22}$ (see Supplementary Note 5 for details). The free energy profile for IS $\mathrm{Rb}^{+}$is deeper than $\mathrm{OS}^{2} b^{+}$, reflecting thermodynamic stability of $\mathrm{IS} \mathrm{Rb}^{+}$over $\mathrm{OS} \mathrm{Rb}^{+}$. Because IS $\mathrm{Rb}^{+}$is more stable than $\mathrm{OS} \mathrm{Rb}^{+}$by $\sim 6 \mathrm{~kJ} \mathrm{~mol}^{-1}$ (corresponding to $\left|\Delta G^{\circ}{ }_{\mathrm{IS}-\mathrm{OS}}\right|$ in Fig. 6), the energy barrier for the transition from IS to OS for $\mathrm{Rb}^{+}$during desorption $\left(E_{\mathrm{IS} \rightarrow \mathrm{OS}} \approx 18 \mathrm{~kJ} \mathrm{~mol}^{-1}\right)$ is higher than the energy barrier for the transition from OS to IS during adsorption $\left(E_{\mathrm{OS} \rightarrow \mathrm{IS}} \approx 12 \mathrm{~kJ} \mathrm{~mol}^{-1}\right.$; Fig. 6).

The Arrhenius pre-exponential factors for cation adsorption to muscovite mica agree with predictions from classical ion kinetic theory for transport of solutes in a dilute solution ${ }^{46,47}$. The effective collision frequency $\left(J_{\text {ion }}\right)$ of a solute ion within the muscovite surface unit cell area can be calculated as

$$
J_{\text {ion }}=A_{\mathrm{UC}} c\left[k_{\mathrm{B}} \mathrm{T} /(2 \pi m)\right]^{1 / 2}
$$

where $c$ is the bulk ion concentration (atom $\AA^{-3}$ ), $k_{\mathrm{B}}$ is the Boltzmann constant $\left(\mathrm{J} \mathrm{K}^{-1}\right)$, T is temperature $(\mathrm{K})$ and $m$ is ion mass (= standard atomic weight $/ N_{\mathrm{A}}$ where $N_{\mathrm{A}}$ is Avogadro's number). For $\mathrm{Rb}^{+}$in a $3 \mathrm{mM} \mathrm{RbCl}$ solution, $J_{\text {ion }}=5 \times 10^{7} \mathrm{~s}^{-1}$, a value similar to that fit to the XR data, $A_{\mathrm{ads}}=8.5 \times 10^{7} \mathrm{~s}^{-1}$ (Table 2). For $\mathrm{Na}^{+}$in a $30 \mathrm{mM} \mathrm{NaCl}$ solution, $J_{\text {ion }}=\sim 1 \times 10^{9} \mathrm{~s}^{-1}$, also in good agreement with $A_{\mathrm{ads}}=2 \times 10^{9} \mathrm{~s}^{-1}$. This agreement for both cations indicates that the attempt frequency for the counterion adsorption reaction on this charged muscovite surface is controlled by bulk ion diffusion and confirms the accuracy of our analysis.
In contrast, the pre-exponential factors for desorption, $\sim 3 \times 10^{4}$ for $\mathrm{Rb}^{+}$and $\sim 5 \times 10^{4} \mathrm{~s}^{-1}$ for $\mathrm{Na}^{+}$, were significantly smaller than the values $\left(\geq 10^{10} \mathrm{~s}^{-1}\right.$; ref. 48) expected for an elementary desorption process. For a simple interfacial system, such as a metal-vacuum interface, the attempt frequency for desorption is reported to be similar to the vibrational frequency of the adsorbate ${ }^{48,49}$. The observed small pre-exponential factors, therefore, indicate that desorption of a cation from the muscovite-water interface is intrinsically complex. It is proposed that cations undergo multiple steps in the process of detaching from the interface, for example, transformation from IS to OS complexes. Cations adsorbed at the muscovite surface are reported to have strong correlations with surrounding water molecules and even with neighbouring ions at higher adsorbed coverages $^{31,32}$. Desorption of cations from the interface likely involves the correlated motion of multiple interfacial species. The motion of interfacial species can also be dampened by the increased viscosity of water near the charged surface. Computational studies ${ }^{21,50,51}$ showed that interfacial water near charged surfaces is more viscous than bulk water, as a result of the formation of well-ordered hydration layers near the surface ${ }^{52-55}$. Surface force apparatus ${ }^{30}$ and in situ XR measurements ${ }^{22,56}$ also confirmed experimentally the presence of structured interfacial water having a characteristic oscillation in density extending up to $10-15 \AA$ from the muscovite surface.

The energy associated with disruption and reconfiguration of the interfacial hydration network can explain the magnitude of the observed activation energies for cation adsorption and desorption. In this context, the similarity of the activation energies for adsorption and desorption with the standard-state Gibbs free energy for the surface hydration of muscovite (between 10 and $20 \mathrm{~kJ} \mathrm{~mol}^{-1}$; ref. 57) is expected. However, the observed $E_{\mathrm{a}}$ values $\left(26-40 \mathrm{~kJ} \mathrm{~mol}^{-1}\right.$; Table 2) are higher, indicating that additional energy is required to explain the difference. We note that adsorption and desorption processes also involve the (partial) disruption of the hydration shells around the cations. The relative differences in activation energies for $\mathrm{Na}^{+}$and $\mathrm{Rb}^{+}$can be understood by the relative differences in the ion hydration energies, that is, there is a larger barrier to adsorption for the more strongly hydrated $\mathrm{Na}^{+}$. However, the activation energies are substantially smaller in magnitude than the hydration free energies for the cations $\left(-365 \mathrm{~kJ} \mathrm{~mol}^{-1}\right.$ for $\mathrm{Na}^{+}$and $-275 \mathrm{~kJ} \mathrm{~mol}^{-1}$ for $\mathrm{Rb}^{+}$; ref. 40$)$, indicating that adsorption and desorption likely involves only a small change of the coordinating structure of the cations, for example, via ligand exchange between water molecules in the ion hydration shell and oxygen atoms on the muscovite surface.

Our measurements, to the best of our knowledge, are the first to monitor simultaneously the structure, kinetics and dynamics at a solid-water interface with molecular-scale sensitivity. Exchange kinetics of monovalent cations at the negatively charged muscovite surface were described using a simple kinetic model for the primary rate-limiting step reaction to provide a general understanding of how adsorbed cations change their coverage and speciation at this idealized interfacial system. These processes may be more complex when viewed with a better time resolution and over an extended range of temperature. Properties of adsorbates can also influence the interfacial thermodynamics and kinetics, especially for multivalent cations (for example, $\mathrm{Sr}^{2+}$ or $\left.\mathrm{Y}^{3+}\right)^{39,58}$ whose adsorption can be modified by ion-ion correlations ${ }^{59,60}$. In other interfacial systems where ions adsorb chemically to surface functional groups, we expect that larger activation energies will be observed when adsorption/desorption reactions involve the creation and breakage of chemical bonds (for example, on oxide surfaces) ${ }^{1,61}$. 
These real-time observations of interfacial dynamics during cation exchange can have wide applicability for understanding reactions at various liquid-solid interfaces. For example, they can provide a fundamental basis for predictive models that describe the transport of dissolved species (for example, nutrients, contaminants) in natural systems or the effectiveness of water purification methods ${ }^{62,63}$ where ion exchange is a rate-limiting step. The quantitative description of ion exchange at the molecular scale can be used to understand and/or design chemical processes, such as nucleation, growth and dissolution of solids for which adsorption and desorption of constituent ions are the elementary steps, or to investigate the fundamental limitations of charge and discharge rates in supercapacitors ${ }^{11,64}$ where the mechanism of energy storage involves adsorption and desorption processes.

\section{Methods}

Sample preparation. Experimental solutions were prepared by dissolving high-purity rubidium chloride or sodium chloride in deionized water (18.2 M $\Omega$ $\mathrm{cm})$. The final concentrations were 3 and $30 \mathrm{mM}$ for $\mathrm{Rb}^{+}$and $\mathrm{Na}^{+}$, respectively. In each solution, the cation coverage on the mica surface is calculated to be $97 \%$ and $90 \%$, respectively, using the intrinsic adsorption constants for $\mathrm{Rb}^{+}$and $\mathrm{Na}^{+}$(refs 35,39). The solution $\mathrm{pH}$ was adjusted to 7.5 using a small amount of $0.1 \mathrm{M} \mathrm{NaOH}$ to reduce the competition from hydronium ${ }^{39}$. A gem-quality muscovite crystal from Asheville Schoonmaker Mica Company was prepared with dimensions of $2.5 \times 25 \times 0.2 \mathrm{~mm}^{3}$. The crystal was cleaved using tape, rinsed with deionized water and transferred to an in situ flow-through X-ray transmission cell (Supplementary Fig. 1) ${ }^{43}$.

X-ray measurements. X-ray experiments were conducted at beamlines 6-ID-B and 33-ID-D, Advanced Photon Source at the Argonne National Laboratory. The incident X-ray beam was focused vertically using a Kirkpatrick-Baez mirror to have a beam size of $0.02-0.05 \mathrm{~mm}$ (vertical) $\times 0.5-1.0 \mathrm{~mm}$ (horizontal) at the sample location with a flux of $\sim 5 \times 10^{11}$ photons $\mathrm{s}^{-1}$. The X-ray beam reflected at the mica-solution interface was collected using an $\mathrm{X}$-ray charged-couple device detector as a function of time at a fixed momentum transfer $q=0.488 \AA^{-1}$. This scattering condition was chosen to enhance the sensitivity of XR to the total coverage and average height of $\mathrm{Rb}^{+}$adsorbed at the interface ${ }^{35,39}$. TRAXR data were obtained from a series of TXR data. The reflectivity at a given time was extracted from each TXR curve by linear interpolation, and the points calculated at 34 different photon energies near $E_{\mathrm{o}}$ at the same time were combined to yield a TRAXR spectrum at this given time. Each spectrum was analysed using model-independent RAXR analyses ${ }^{42}$ following the procedure described previously ${ }^{35}$

Data availability. The data that support the findings of this study are available from the corresponding authors on request.

\section{References}

1. Fuller, C. C., Davis, J. A. \& Waychunas, G. A. Surface chemistry of ferrihydrite: Part 2. Kinetics of arsenate adsorption and coprecipitation. Geochim. Cosmochim. Acta 57, 2271-2282 (1993).

2. Tanaka, D. et al. Rapid preparation of flexible porous coordination polymer nanocrystals with accelerated guest adsorption kinetics. Nat. Chem. 2, 410-416 (2010).

3. Hasell, T., Schmidtmann, M. \& Cooper, A. I. Molecular doping of porous organic cages. J. Am. Chem. Soc. 133, 14920-14923 (2011).

4. Stack, A. G., Raiteri, P. \& Gale, J. D. Accurate rates of the complex mechanisms for growth and dissolution of minerals using a combination of rare-event theories. J. Am. Chem. Soc. Commun. 134, 11-14 (2012).

5. Sumida, K. et al. Carbon dioxide capture in metal-organic frameworks. Chem. Rev. 112, 724-781 (2012).

6. Over, H. et al. Atomic-scale structure and catalytic reactivity of the $\mathrm{RuO}_{2}(110)$ surface. Science 287, 1474-1476 (2000).

7. Joo, S. H. et al. Ordered nanoporous arrays of carbon supporting high dispersions of platinum nanoparticles. Nature 412, 169-172 (2001).

8. Matsuda, R. et al. Highly controlled acetylene accommodation in a metalorganic microporous material. Nature 436, 238-241 (2005).

9. Stamenkovic, V. R. et al. Improved oxygen reduction activity on $\mathrm{Pt}_{3} \mathrm{Ni}(111)$ via increased surface site availability. Science 315, 493-497 (2007).

10. Ma, L. Q., Falkowski, J. M., Abney, C. \& Lin, W. B. A series of isoreticular chiral metal-organic frameworks as a tunable platform for asymmetric catalysis. Nat. Chem. 2, 838-846 (2010).
11. Chmiola, J. et al. Anomalous increase in carbon capacitance at pore sizes less than 1 nanometer. Science 313, 1760-1763 (2006).

12. Kang, B. \& Ceder, G. Battery materials for ultrafast charging and discharging. Nature 458, 190-193 (2009).

13. Merlet, C. et al. Highly confined ions store charge more efficiently in supercapacitors. Nat. Commun. 4, 2701 (2013).

14. Liu, J., Wickramaratne, N. P., Qiao, S. Z. \& Jaroniec, M. Molecular-based design and emerging applications of nanoporous carbon spheres. Nat. Mater. 14, 763-774 (2015).

15. Gouy, M. Sur la constitution de la charge électrique à la surface d'un électrolyte. J. Phys. Théor. Appl. 9, 457-468 (1910).

16. Chapman, D. L. A contribution to the theory of electrocapillarity. Philos. Mag 25, 475-481 (1913).

17. Stern, H. O. Zur Theorie der elektrolytischen Doppelschicht (The theory of the electrolytic double-layer). Z. Electrochem. 30, 508-516 (1924).

18. James, R. O. \& Healy, T. W. Adsorption of hydrolyzable metal ions at the oxide-water interface. J. Colloid Interface Sci. 40, 65-81 (1972).

19. Sverjensky, D. A. Physical surface-complexation models for sorption at the mineral-water interface. Nature 364, 776-780 (1993).

20. Lee, S. S., Fenter, P., Park, C., Sturchio, N. C. \& Nagy, K. L. Hydrated cation speciation at the muscovite (001)-water interface. Langmuir 26, 16647-16651 (2010).

21. Bourg, I. C. \& Sposito, G. Molecular dynamics simulations of the electrical double layer on smectite surfaces contacting concentrated mixed electrolyte $\left(\mathrm{NaCl}-\mathrm{CaCl}_{2}\right)$ solutions. J. Colloid Interface Sci. 360, 701-715 (2011).

22. Lee, S. S., Fenter, P., Nagy, K. L. \& Sturchio, N. C. Monovalent ion adsorption at the muscovite (001) - solution interface: relationships among ion coverage and speciation, interfacial water structure, and substrate relaxation. Langmuir 28, 8637-8650 (2012).

23. Laio, A. \& Parrinello, M. Escaping free-energy minima. Proc. Natl Acad. Sci. USA 99, 12562-12566 (2002)

24. Henin, J., Fiorin, G., Chipot, C. \& Klein, M. L. Exploring multidimensional free energy landscapes using time-dependent biases on collective variables. J. Chem. Theor. Comput. 6, 35-47 (2010).

25. Zheng, S. H. \& Pfaendtner, J. Enhanced sampling of chemical and biochemical reactions with metadynamics. Mol. Simul. 41, 55-72 (2015).

26. Schlegel, M. L. et al. Cation sorption on the muscovite (001) surface in chloride solutions using high-resolution X-ray reflectivity. Geochim. Cosmochim. Acta 70, 3549-3565 (2006).

27. Pashley, R. M. Hydration forces between mica surfaces in aqueous electrolyte solutions. J. Colloid Interface Sci. 80, 153-162 (1981).

28. Pashley, R. M. DLVO and hydration forces between mica surfaces in $\mathrm{Li}^{+}$, $\mathrm{Na}^{+}, \mathrm{K}^{+}$, and $\mathrm{Cs}^{+}$electrolyte solutions: a correlation of double-layer and hydration forces with surface cation exchange properties. J. Colloid Interface Sci. 83, 531-546 (1981).

29. Israelachvili, J. N. \& Pashley, R. M. Molecular layering of water at surfaces and origin of repulsive hydration forces. Nature 306, 249-250 (1983).

30. Israelachvili, J. N. \& Wennerström, H. Role of hydration and water structure in biological and colloidal interactions. Nature 379, 219-225 (1996).

31. Ricci, M., Spijker, P. \& Voïtchovsky, K. Water-induced correlation between single ions imaged at the solid-liquid interface. Nat. Commun. 5, 4400 (2014).

32. Martin-Jimenez, D., Chacon, E., Tarazona, P. \& Garcia, R. Atomically resolved three-dimensional structures of electrolyte aqueous solutions near a solid surface. Nat. Commun. 7, 7 (2016).

33. Park, C., Fenter, P. A., Nagy, K. L. \& Sturchio, N. C. Hydration and distribution of ions at the mica-water interface. Phys. Rev. Lett. 97, 016101 (2006).

34. Sakuma, H., Kondo, T., Nakao, H., Shiraki, K. \& Kawamura, K. Structure of hydrated sodium ions and water molecules adsorbed on the mica/water interface. J. Phys. Chem. C 115, 15959-15964 (2011).

35. Lee, S. S., Fenter, P., Nagy, K. L. \& Sturchio, N. C. Changes in adsorption free energy and speciation during competitive adsorption between monovalent cations at the muscovite (001)-water interface. Geochim. Cosmochim. Acta 123 416-426 (2013).

36. Pintea, S. et al. Solid-liquid interface structure of muscovite mica in $\mathrm{CsCl}$ and RbBr solutions. Langmuir 32, 12955-12965 (2016).

37. Sakuma, H. \& Kawamura, K. Structure and dynamics of water on $\mathrm{Li}^{+}-, \mathrm{Na}^{+}$, $\mathrm{K}^{+}$-, $\mathrm{Cs}^{+}{ }_{-}, \mathrm{H}_{3} \mathrm{O}^{+}$-exchanged muscovite surfaces: a molecular dynamics study. Geochim. Cosmochim. Acta 75, 63-81 (2011).

38. Teich-McGoldrick, S. L., Greathouse, J. A. \& Cygan, R. T. Molecular dynamics simulations of uranyl adsorption and structure on the basal surface of muscovite. Mol. Simul. 40, 610-617 (2014).

39. Park, C., Fenter, P. A., Sturchio, N. C. \& Nagy, K. L. Thermodynamics, interfacial structure, and $\mathrm{pH}$ hysteresis of $\mathrm{Rb}^{+}$and $\mathrm{Sr}^{2+}$ adsorption at the muscovite (001)-solution interface. Langmuir 24, 13993-14004 (2008).

40. Marcus, Y. Thermodynamics of solvation of ions. J. Chem. Soc. Faraday Trans. 87, 2995-2999 (1991). 
41. Skipper, N. T., Chang, F.-R.C. \& Sposito, G. Monte-Carlo simulation of interlayer molecular-structure in swelling clay-minerals. 1. Methodology. Clays Clay Miner. 43, 285-293 (1995).

42. Park, C. \& Fenter, P. A. Phasing of resonant anomalous X-ray reflectivity spectra and direct Fourier synthesis of element-specific partial structures at buried interfaces. J. Appl. Crystallogr. 40, 290-301 (2007).

43. Lee, S. S., Fenter, P. \& Park, C. Optimizing a flow-through X-ray transmission cell for studies of temporal and spatial variations of ion distributions at mineral-water interfaces. J. Synchrotron Radiat. 20, 125-136 (2013).

44. Langmuir, D. Aqueous Environmental Geochemistry (Prentice-Hall Inc., 1997).

45. Boudart, M. Kinetics of Chemical Processes (Prentice-Hall Inc., 1968).

46. Jung, L. S. \& Campbell, C. T. Sticking probabilities in adsorption from liquid solutions: alkylthiols on gold. Phys. Rev. Lett. 84, 5164-5167 (2000).

47. Jung, L. S. \& Campbell, C. T. Sticking probabilities in adsorption of alkanethiols from liquid ethanol solution onto gold. J. Phys. Chem. B 104, 11168-11178 (2000).

48. Zhdanov, V. P. Arrhenius parameters for rate processes on solid surfaces. Surf. Sci. Rep. 12, 183-242 (1991)

49. Zangwill, A. Physics at Surfaces (Cambridge University, 1988).

50. Duan, C. H. \& Majumdar, A. Anomalous ion transport in 2-nm hydrophilic nanochannels. Nat. Nanotechnol. 5, 848-852 (2010).

51. Holmboe, M. \& Bourg, I. C. Molecular dynamics simulations of water and sodium diffusion in smectite interlayer nanopores as a function of pore size and temperature. J. Phys. Chem. C 118, 1001-1013 (2014).

52. Lee, S. H. \& Rossky, P. J. A comparison of the structure and dynamics of liquid water at hydrophobic and hydrophilic surfaces-a molecular-dynamics simulation study. J. Chem. Phys. 100, 3334-3345 (1994).

53. Toney, M. F. et al. Voltage-dependent ordering of water-molecules at an electrode-electrolyte interface. Nature 368, 444-446 (1994)

54. Castrillon, S. R. V., Giovambattista, N., Aksay, I. A. \& Debenedetti, P. G. Structure and energetics of thin film water. J. Phys. Chem. C 115, 4624-4635 (2011).

55. Fenter, P. \& Lee, S. S. Hydration layer structure at solid-water interfaces. MRS Bull. 39, 1056-1061 (2014).

56. Cheng, L., Fenter, P., Nagy, K. L., Schlegel, M. L. \& Sturchio, N. C. Molecularscale density oscillations in water adjacent to a mica surface. Phys. Rev. Lett. 87, 156103 (2001)

57. Cantrell, W. \& Ewing, G. E. Thin film water on muscovite mica. J. Phys. Chem. B 105, 5434-5439 (2001).

58. Lee, S. S., Schmidt, M., Laanait, N., Sturchio, N. C. \& Fenter, P. Investigation of adsorbed structure, adsorption free energy, and overcharging behavior of trivalent yttrium at the muscovite (001)-water interface. J. Phys. Chem. C 117, 23738-23749 (2013).

59. Shklovskii, B. I. Screening of a macroion by multivalent ions: correlationinduced inversion of charge. Phys. Rev. E 60, 5802-5811 (1999).

60. Levin, Y. Electrostatic correlations: from plasma to biology. Rep. Prog. Phys. 65, 1577-1632 (2002)

61. Raven, K. P., Jain, A. \& Loeppert, R. H. Arsenite and arsenate adsorption on ferrihydrite: kinetics, equilibrium, and adsorption envelopes. Environ. Sci. Technol. 32, 344-349 (1998).

62. DeMarco, M. J., Sengupta, A. K. \& Greenleaf, J. E. Arsenic removal using a polymeric/inorganic hybrid sorbent. Water Res. 37, 164-176 (2003).

63. Ali, I. \& Gupta, V. K. Advances in water treatment by adsorption technology. Nat. Protoc. 1, 2661-2667 (2006).

64. Kondrat, S., Wu, P., Qiao, R. \& Kornyshev, A. A. Accelerating charging dynamics in subnanometre pores. Nat. Mater. 13, 387-393 (2014).

65. Lee, S. S., Park, C., Fenter, P., Sturchio, N. C. \& Nagy, K. L. Competitive adsorption of strontium and fulvic acid at the muscovite-solution interface observed with resonant anomalous X-ray reflectivity. Geochim. Cosmochim. Acta 74, 1762-1776 (2010).

\section{Acknowledgements}

This work was supported by US Department of Energy, Office of Science, Office of Basic Energy Sciences, Chemical Sciences, Geosciences, and Biosciences Division under Contracts DE-AC02-06CH11357 to UChicago Argonne LLC, as operator of the Argonne National Laboratory. The manuscript was created at UChicago Argonne, LLC, Operator of Argonne National Laboratory ('Argonne'). Argonne, a US Department of Energy Office of Science laboratory, is operated under Contract DE-AC02-06CH11357. The US Government retains for itself, and others acting on its behalf, a paid-up nonexclusive, irrevocable worldwide licence in said article to reproduce, prepare derivative works, distribute copies to the public and perform publicly and display publicly by or on behalf of the Government. The X-ray data were collected at beamlines 6-ID-B and 33-ID-D, Advanced Photon Source. Use of the Advanced Photon Source was supported by the US Department of Energy, Office of Science, Office of Basic Energy Sciences, under Contract DE-AC02-06CH11357 to UChicago Argonne LLC, as operator of the Argonne National Laboratory. We thank Ian C. Bourg (Princeton University), Aurora E. Clark (Washington State University) and two anonymous reviewers for insightful comments and discussions of the results.

\section{Author contributions}

S.S.L. and P.F. designed the study. S.S.L. carried out the experimental measurements and data analysis. All authors discussed the results and contributed to the interpretation of data. All authors contributed to editing the manuscript.

\section{Additional information}

Supplementary Information accompanies this paper at http://www.nature.com/ naturecommunications

Competing interests: The authors declare no competing financial interests.

Reprints and permission information is available online at http://npg.nature.com/ reprintsandpermissions/

How to cite this article: Lee, S. S. et al. Real-time observation of cation exchange kinetics and dynamics at the muscovite-water interface. Nat. Commun. 8, 15826 doi: $10.1038 /$ ncomms15826 (2017)

Publisher's note: Springer Nature remains neutral with regard to jurisdictional claims in published maps and institutional affiliations.

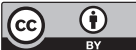

Open Access This article is licensed under a Creative Commons Attribution 4.0 International License, which permits use, sharing, adaptation, distribution and reproduction in any medium or format, as long as you give appropriate credit to the original author(s) and the source, provide a link to the Creative Commons license, and indicate if changes were made. The images or other third party material in this article are included in the article's Creative Commons license, unless indicated otherwise in a credit line to the material. If material is not included in the article's Creative Commons license and your intended use is not permitted by statutory regulation or exceeds the permitted use, you will need to obtain permission directly from the copyright holder. To view a copy of this license, visit http://creativecommons.org/ licenses/by/4.0/

(C) The Author(s) 2017 